\title{
Verleihung der Staufermedaille in Gold an den langjährigen Vorsitzenden der Württembergischen Bibliotheksgesellschaft, Herrn Professor Dr. Wulf D. von Lucius
}

Am 2. August wurde dem langjährigen Vorsitzenden der Württembergischen Bibliotheksgesellschaft, Herrn Professor Dr. Wulf D. von Lucius, eine besondere Auszeichnung zuteil: ihm wurde vom Ministerpräsidenten des Landes BadenWürttemberg die Staufermedaille in Gold verliehen. Mit dieser Medaille wurden seine Verdienste um das Gemeinwohl geehrt, die er über viele Jahre hinweg ehrenamtlich erbrachte. Bei der Begrüßung des zu Ehrenden, dessen Familie, Weggefährten und Freunden zeigte sich der Direktor der Württembergischen Landesbibliothek, Dr. Rupert Schaab, besonders erfreut, dass Herr Professor von Lucius gerade die Landesbibliothek als Ort für diese Ehrung gewählt hatte.

In ihrer Würdigung hob Petra Olschowski, Staatssekretärin im Ministerium für Wissenschaft, Forschung und Kunst Baden-Württemberg, die in Stellvertretung des Ministerpräsidenten die Auszeichnung überreichte, die Verdienste Herrn Prof. von Lucius um die WLB hervor. Wo immer er konnte, setzte er sich für die Interessen der Landesbibliothek ein und konnte dadurch nicht nur die Bestände der Bibliothek um wertvolle Stücke bereichern, sondern auch mit seinem 2015 ins Leben gerufenen Projekt der "Buchpatenschaften" dazu beitragen, die Altbestände zu restaurieren. Seiner Initiative ist es zudem zu verdanken, dass die Bibliotheksgesellschaft 2006 eine Machbarkeitsstudie für die Realisierung des Erweiterungsbaus finanzierte und in Auftrag gab. Auch überregional engagierte er sich für das Verlags-, Buch- und Bibliothekswesen.

\section{Die Biographie des zu Ehrenden ist in Stuttgart} untrennbar mit dem Kulturgut „Buch" verbunden. Dem ursprünglich aus Jena, seinem Geburtsort, stammenden Gustav Fischer Verlag, stand Prof. von Lucius bis 1996 als geschäftsführender Gesell- schafter vor. Im gleichen Jahr gründete der promovierte Volkswirt zusammen mit seiner Ehefrau Akka den Stuttgarter Fachverlag für Wirtschafts- und Sozialwissenschaft Lucius \& Lucius. Er engagierte sich als langjähriger Vorsitzender des Verlegerausschusses im Börsenverein des deutschen Buchhandels für das Urheberrecht und war mehr als 25 Jahre Lehrbeauftragter an der Universität Hohen- 
des Börsenvereins, sowie die Zugehörigkeit zum Vorstand der Deutschen Schillergesellschaft e.V. in den Jahren 1989 bis 2009. Zudem arbeitete er ehrenamtlich für die Wüstenrot-Stiftung und die Deutsche Nationalbibliothek.

Die Laudatio schloss mit den Worten: „Die Bücherlust - so der Titel eines seiner Bücher - ist Teil seines Lebensglücks."
Die Feier wurde musikalisch vom Gitarristen Jonas Khalil mit einer "Fantasia Bachiana" und der eigenen Bearbeitung von Jaques Duphlys "La Victoire" untermalt. Beim anschließenden Empfang hatten alle Anwesenden die Gelegenheit, sich über die außergewöhnliche "bibliophile Biographie" des Geehrten auszutauschen und inm herzlich für die großartige Auszeichnung zu gratulieren.

Eva-Maria Voerster

\section{Unterstützen Sie die Württembergische Landesbibliothek.}

\section{Werden Sie Mitglied \\ in der Württembergischen Bibliotheksgesellschaft!}
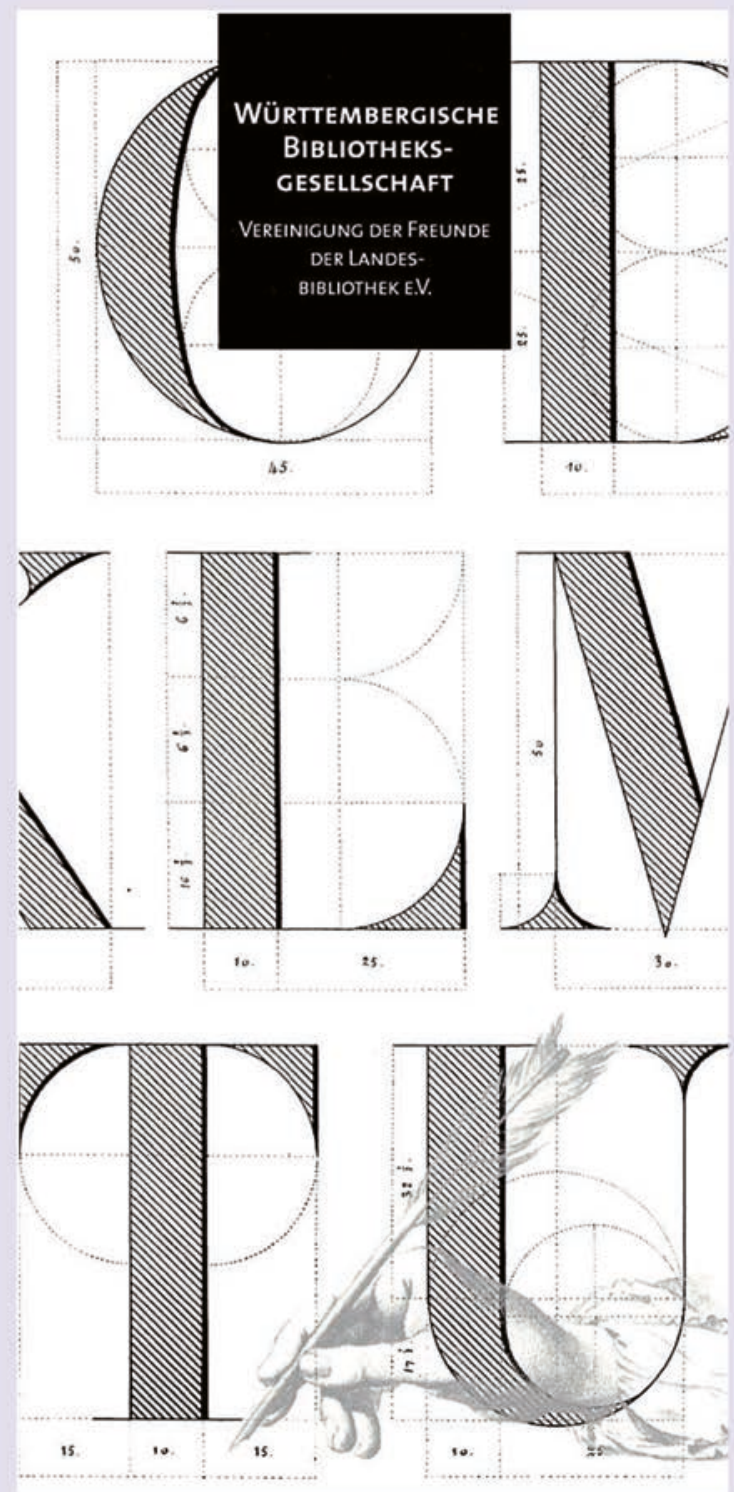

Kontakt: Württembergische Bibliotheksgesellschaft Tel.: 0711/212-4428; Fax: 0711/212-4422; E-Mail: wbg@wlb-stuttgart.de 